\title{
A influência da informação prévia na escolha de websites em mecanismos de busca
}

\author{
The prior information influence on website choice in search engines \\ La influencia de la información previa en la elección del sitio web en los motores de búsqueda
}

Recebido: 11/12/2021 | Revisado: 17/12/2021 | Aceito: 22/12/2021 | Publicado: 25/12/2021

\author{
João Vicente Rosa de Souza \\ ORCID: https://orcid.org/0000-0002-3631-3864 \\ Universidade de São Caetano do Sul, Brasil \\ E-mail: joaovsouza@gmail.com \\ Silvio Augusto Minciotti \\ ORCID: https://orcid.org/0000-0002-3928-8107 \\ Universidade de São Caetano do Sul, Brasil \\ E-mail: silvio.minciotti@online.uscs.edu.br
}

\begin{abstract}
Resumo
Este artigo aborda a importância e as consequências da otimização de posicionamento de site no ranking de resultados em uma busca na internet. Dessa forma, optou-se pelo método experimental, composto por uma simulação de acesso a um site de pesquisa em conjunto com um questionário fechado, caracterizando a captação de dados como quantitativa. $\mathrm{O}$ experimento, de desenho fatorial de ordem um, onde manipulou-se a informação prévia dos participantes, foi aplicado em 70 estudantes de uma faculdade do norte do Estado do Rio Grande do Sul. Desse modo, foram convidados a participar do estudo alunos de cursos de graduação em Administração de Empresas e Direito. Os resultados encontrados demonstraram a influência e relevante importância da informação prévia, comprovando para as empresas que esse tipo de ferramenta deve ser priorizada no ambiente de comércio virtual. Constatou-se, também, que consumidores que possuem menos informações sobre o produto tendem a visitar os primeiros sites listados como resultados da busca.
\end{abstract}

Palavras-chave: Comportamento do consumidor; Sites de pesquisa; Otimização; SEO; SEM.

\begin{abstract}
This article discusses the importance and consequences of website positioning optimization in the results ranking in an internet search. Thus, an experiment was carried out consisting of a simulation of access to a research site together with a questionnaire, characterizing data collection as quantitative. The experiment was applied to 70 students from a college in the north of the state of Rio Grande do Sul. In this way, students from undergraduate courses in Business Administration and Law were invited to participate in the study. The results demonstrated the influence and relevant importance of prior information, proving to companies that this type of tool should be prioritized in the virtual commerce environment. It was also found that consumers who have less information about the product tend to visit the first sites listed as search results.
\end{abstract}

Keywords: Consumer behavior; Search sites; Optimization; SEO; SEM.

\begin{abstract}
Resumen
Este artículo analiza la importancia y las consecuencias de la optimización del posicionamiento de un sitio web en el ranking de resultados de una búsqueda en Internet. Así, se optó por el método experimental, consistente en una simulación de acceso a un sitio de investigación junto con un cuestionario cerrado, caracterizando la recogida de datos como cuantitativa. El experimento, con un diseño factorial de orden uno, que manipuló la información previa de los participantes, se aplicó a 70 estudiantes de una facultad del norte del estado de Rio Grande do Sul. Licenciada en Administración de Empresas y Derecho. Los resultados encontrados demuestran la influencia y relevancia de la información previa, demostrando para las empresas que este tipo de herramientas deben ser priorizadas en el entorno del comercio electrónico. También se encontró que los consumidores que tienen menos información sobre el producto tienden a visitar los primeros sitios listados como resultados de búsqueda.
\end{abstract}

Palabras clave: Comportamiento del consumidor; Búsqueda de sitios web; Optimización; SEO; SEM.

\section{Introdução}

A ampla adoção de tecnologias digitais e das redes sociais online revolucionaram a maneira como as empresas se envolvem com os consumidores (Krishen et al., 2021). Dessa forma, com o aumento do uso dos meios digitais, a visibilidade na web se tornou essencial para organizações quando atendem a um mercado-alvo mais amplo (Aswani et al., 2021). Além 
disso, o ambiente de consumo em tempo real e o crescimento dos mecanismos de busca na web assumem-se como tendências marcantes, exigindo das organizações uma postura permanente de atualização e estratégias mercadológicas dirigidas a essas tendências (Okada \& Souza, 2011). Neste sentido, a ampliação dessa visibilidade na web está diretamente relacionada à forma como os consumidores pesquisam por produtos nos mecanismos de busca disponíveis na internet, bem como aos fatores que os influenciam ao se envolverem num processo de busca por informações acerca de um produto (Aswani et al., 2021).

No Brasil, o sistema de busca orgânico ainda se apresenta como um assunto novo, embora já tenha sido alvo de estudos em outros países (Aswani et al., 2021; Terrance et al., 2018; Terrance et al., 2017; Dou et al., 2010; Jansen \& Molina, 2006). Dou et. al. (2010) relatam em seus estudos que a otimização do posicionamento de pesquisa na web é um fator de grande importância para as empresas, pois aumenta consideravelmente seus acessos e também sua avaliação, assim como, a otimização pode vir a influenciar diretamente no sucesso de um comércio online. Ou seja, muito do tráfego gerado para os websites das empresas advém dos mecanismos de busca na internet, tais como Google, Bing e Yahoo, para nomear alguns (Aswani et al., 2021). Já Jansen e Molina (2006) apresentam que os endereços de sites mostrados organicamente pelo Google foram mais relevantes no processo de decisão de acesso do que os sponsored links, que são os endereços pagos pelas empresas para aparecerem por primeiro, ou seja, eles definem em sua conclusão que as empresas podem até pagar para ter um posicionamento diferenciado em uma página de busca na web, porém, não devem deixar de lado a otimização de seus resultados orgânicos junto a esses sites.

Corroboram com esta visão, Terrance et. al. (2018) ao afirmar que websites ranqueados nos primeiros lugares nos mecanismos de busca recebem mais tráfego de visitantes, que podem ser convertidos em consumidores e, consequentemente, em vendas. A relevância das conclusões citadas é sustentada por estatísticas promissoras, uma vez que, observou-se o crescimento de $41 \%$ do e-commerce em 2020, impulsionado pela pandemia do Coronavírus, comparado a 2019 (Ebit Nielsen, 2021).

Além disso, um elemento fundamental quando o consumidor está envolvido no processo de escolha por um website é a quantidade de informação acerca do produto que está sendo pesquisado que ele possui. Afinal, o fato de o consumidor possuir ou não informações sobre um determinado produto demonstrou influenciar no seu processo de decisão de compra (Godey et al., 2016; Salerno et al., 2015; Kivetz \& Simonson, 2000).

Percebe-se, portanto, a importância de as empresas compreenderem o funcionamento da otimização dos resultados em sites de busca, responsáveis por grande parte dos acessos aos websites de empresas. Não obstante, entende-se de grande relevância o entendimento do papel das informações de que o consumidor dispõe no seu comportamento de escolha de websites ao realizar uma busca por palavras-chave. Diante do exposto, o objetivo deste estudo foi testar a influência da informação prévia na escolha de websites em mecanismos de busca.

\section{Metodologia}

Acompanhando o objetivo do trabalho, que foi testar se existe uma influência direta da informação prévia sobre um produto na escolha do consumidor por um website ao pesquisar em um mecanismo de busca, optou-se pelo método experimental. Um experimento é um projeto de pesquisa que envolve a manipulação de uma ou mais variáveis enquanto outras são mantidas constantes, e a posterior medição dos resultados (Malhotra, 2012). A explicação do autor embasa a característica desse experimento, no qual utilizou-se a informação prévia como variável a ser manipulada, conforme detalhado a seguir.

Desenho do experimento e participantes: $\mathrm{O}$ estudo foi realizado em um desenho fatorial de ordem um: prévia informação sobre produto pesquisado ( $\operatorname{sim} \mathrm{X}$ não). Ao primeiro grupo, não foi apresentada informação acerca do produto em questão que seria pesquisado. Em contrapartida, ao segundo grupo foi apresentada informação acerca do produto. Os participantes tiveram acesso a apenas um dos cenários (com ou sem informação prévia). 
Os participantes desta pesquisa foram 70 estudantes de uma faculdade, distribuídos aleatoriamente em cada um dos grupos (35 alunos por condição). Quanto ao sexo, 47,1\% eram do sexo masculino e 52,9\% do sexo feminino, e a idade média foi de 24,9 anos.

Procedimentos: Para a realização do estudo, os autores desenvolveram um website no qual era simulado uma situação de pesquisa de informações sobre determinado produto. A coleta de dados foi realizada num laboratório de informática da faculdade em que os respondentes estudavam. Dessa forma, eles foram convidados a participar da pesquisa e levados até o laboratório. Ao chegar, se dirigiam até um computador, em cuja tela o participante lia as orientações e as seguia. Para o grupo com informação prévia sobre a prática de escalada, era apresentado um texto com informações específicas sobre o esporte, enquanto para o outro grupo (sem informação) eram apresentadas as mesmas orientações de participação, mas sem informações acerca do produto em questão.

Ao grupo para o qual eram disponibilizadas informações prévias sobre o esporte e o produto escolhido, cada participante era exposto à prática de escaladas, suas características e os objetos utilizados para praticar o esporte (as informações apresentadas foram coletadas em sites especializados no esporte escalada e compiladas pelos autores). Desse modo, o participante se deparava com a seguinte situação:

A prática de escaladas

A escala é uma atividade desportiva que tem como objetivo principal conseguir ascender a uma superfície (rocha, gelo ou montanha). Trata-se de um desporto de aventura que se destina a todos os que gostam de desafios e de emoções fortes. A prática desse esporte vem sempre acompanhado da aquisição dos objetos indispensáveis para que se tenha uma experiência segura e completa, dentre esses vários objetos, destaca-se a mochila. Algumas características da mochila são essenciais na hora da compra, como por exemplo, o tamanho, regularmente especificado em litros. O mais razoável é que uma mochila para uma atividade como o excursionismo em média ou baixa montanha, tenha um tamanho que oscile entre 55 a 75 litros. A durabilidade é através do tipo de tecido e costura, mais especificamente o tipo de encosto (acolchoamento). Cada mochila incorpora um tipo de encosto, o mais habitual é o anatômico, pré-formado e canalizado nas regiões mais comprimidas para facilitar a ventilação. Outra característica importante é o sistema de encosto aerado, deixando parte central das costas respirar. Várias opções de bolsos, possibilitando o acesso ao interior da mochila mais facilmente, os bolsos serão de grande utilidade para transportar equipamentos, como a lanterna e a garrafa de água. Compartimento com zíper na parte inferior da mochila é muito útil pois deixa o acesso fácil a um conteúdo específico sem desorganizar o restante dos compartimentos. Por último, porém, não menos importante, as mochilas sempre devem possuir o cinto abdominal, pois essa peça torna-se indispensável para repartir a carga entre as regiões mais fortes do corpo. Mais importante que a marca e o preço de uma mochila, são a definição pessoal do que se deseja deste equipamento, seu uso, suas aspirações e etc.

Para ambos os grupos era dada a seguinte orientação:

Você decidiu fazer uma viagem para praticar o esporte radical de escalada, por isso, é necessário comprar a sua mochila. O método escolhido para adquirir o produto foi pela internet, seguindo os conselhos dos seus amigos que lhe acompanharão na viagem. Você, então, dirige-se a um computador com acesso à internet e pesquisa em sites de busca sobre "mochilas para escalada". O monitor mostrará a tela que será apresentada no passo seguinte. Você terá o tempo que precisar para visualizar a página do conteúdo, quando desejar, clique no link que mais lhe interessar.

Dessa forma, os dois grupos foram orientados da mesma maneira acerca da viagem que iriam realizar para praticar o esporte escalada e quanto à necessidade de adquirir uma mochila apropriada para realizar esta prática esportiva. A manipulação ocorreu com relação à disponibilização ou não de informações acerca do produto, a variável independente deste estudo.

Mensurações: Para analisar a variável dependente (website escolhido) foram apresentadas 6 opções de endereços na web que o participante poderia escolher e acessar. Na Figura 1 podem ser visualizados os seis links apresentados para que os 
respondentes pudessem fazer a sua escolha. Essas páginas foram hospedadas em um servidor próprio dos pesquisadores. O layout das páginas do experimento, que envolve a criação de imagens, textos e itens complementares de design, foram adaptados dos estudos de Dou et. al. (2010).

Figura 1 - Página da Web desenvolvida para o estudo.

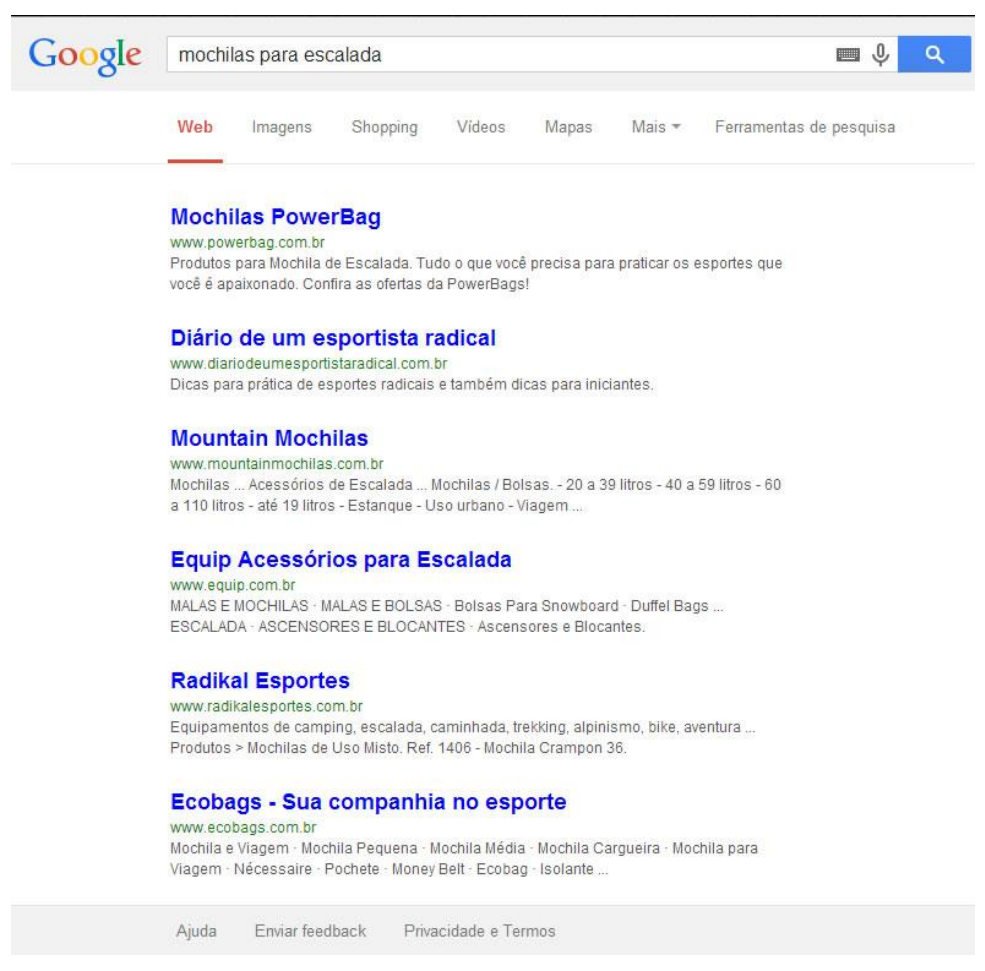

Fonte: Dados da pesquisa (2019).

As respostas à simulação comparando os dois grupos podem ser vistas nos Quadros 1 e 2. A análise escolhida para verificar se as manipulações realizadas trariam os efeitos esperados foi a Análise de Variância (ANOVA). A checagem da manipulação foi feita através da análise entre a variável dependente e as variáveis independentes, confirmando assim, que cada cenário experimental foi percebido de maneira diferente pelos sujeitos que participaram do estudo $(\mathrm{p}<0,005)$. Dessa forma, conforme se observa no Quadro 1, o grupo de respondentes sem informação obteve uma média 1,94, com um desvio-padrão de 1,056. Dos 35 sujeitos que compuseram este grupo, dezessete respondentes escolheram o primeiro link, seis escolheram o segundo link, nove escolheram o terceiro link e três escolheram o quarto link. Nenhum respondente escolheu os links 5 e 6 . Em contrapartida, conforme o Quadro 2, o grupo de respondentes com informação prévia sobre o produto obteve uma média de 3,06, com um desvio-padrão de 1,211. Ainda, percebeu-se uma maior distribuição da escolha entre os links disponíveis, sendo que todos os links tiveram ao menos uma escolha. Assim, neste grupo, três respondentes escolheram o primeiro link, oito escolheram o segundo link, quatorze escolheram o terceiro link, cinco escolheram o quarto link, quatro escolheram o quinto link e um sujeito escolheu o sexto link. 
Quadro 1 - Grupo sem informação prévia.

\begin{tabular}{|c|c|c|c|}
\hline $\begin{array}{l}\text { Opções } \\
\text { de Link }\end{array}$ & Frequência & Média & $\begin{array}{l}\text { Desvio } \\
\text { padrão }\end{array}$ \\
\hline 1 & 17 & \multirow{7}{*}{1,94} & \multirow{7}{*}{1,056} \\
\hline 2 & 6 & & \\
\hline 3 & 9 & & \\
\hline 4 & 3 & & \\
\hline 5 & 0 & & \\
\hline 6 & 0 & & \\
\hline Total & 35 & & \\
\hline
\end{tabular}

Fonte: Dados da pesquisa (2019).
Quadro 2 - Grupo com informação prévia.

\begin{tabular}{|c|c|c|c|}
\hline $\begin{array}{c}\text { Opções } \\
\text { de Link }\end{array}$ & Frequência & \multirow{2}{*}{ Média } & $\begin{array}{c}\text { Desvio } \\
\text { padrão }\end{array}$ \\
\hline 1 & 3 & \multirow{3}{*}{3,06} & \\
\hline 2 & 8 & \multirow{2}{*}{1,211} \\
\hline 3 & 14 & & \\
\hline 4 & 5 & & \\
\hline 5 & 4 & & \\
\hline 6 & 1 & & \\
\hline Total & 35 & & \\
\hline
\end{tabular}

Fonte: Dados da pesquisa (2019).

Variável independente: Para a variável independente utilizou-se a informação prévia sobre o produto pesquisado. A informação prévia efetuou-se de maneira que quando o primeiro grupo (sem informação prévia do produto) atingiu 35 participantes, as telas tiveram sua ordem modificada com a adição da tela com informações sobre o esporte e o produto a ser pesquisado. A Figura 2 retrata a tela apresentada aos respondentes, a qual continha informações referentes à prática esportiva de escalada e ao produto abordado no estudo, mochila para escalada.

Figura 2 - Informação prévia do produto.

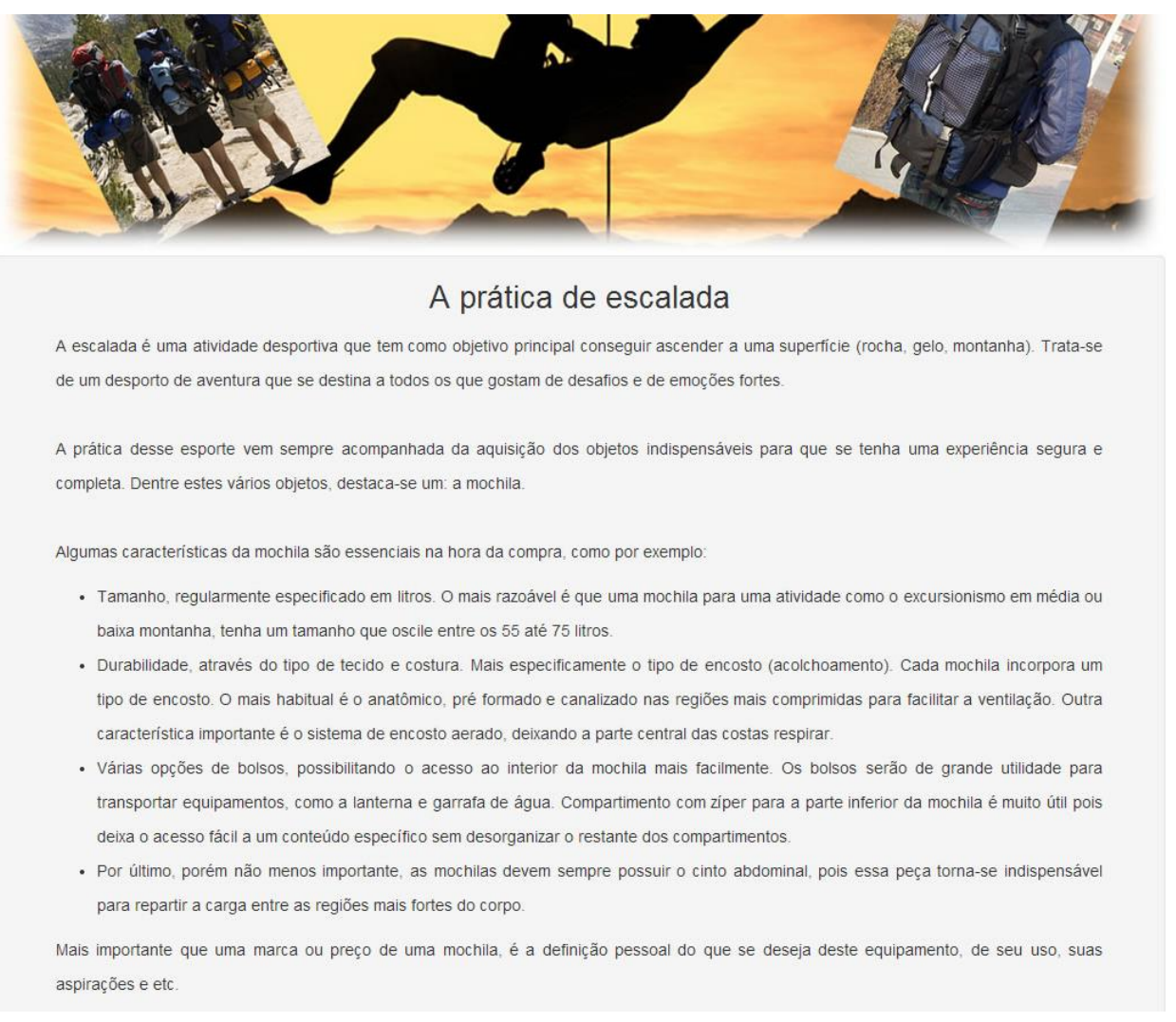

Fonte: Dados da pesquisa (2019).

Variáveis moderadoras: Para as análises das variáveis moderadoras foram aplicadas três perguntas simples, porém, essenciais para detectar a influência ou não das mesmas na variável dependente. Essas variáveis foram consideradas pelo fato de influenciarem no possível efeito da informação prévia, assim como, na variável dependente.

A primeira pergunta é relativa à prática do esporte de escalada. Uma possível influência poderia ocorrer e não ser percebida, caso essa questão não constasse na pesquisa. Ela pode influenciar diretamente na interpretação do experimento, pois 
o respondente apresentaria um grau de conhecimento maior que o do restante (que nunca praticou o esporte), abrindo uma brecha para desvios na análise. Essa questão apresentou 63 respostas negativas (90\% da amostra), desse modo, pessoas que nunca praticaram o esporte, juntamente com 7 respondentes positivos, representando $10 \%$ da amostra.

$\mathrm{Na}$ segunda questão, trata-se do conhecimento anterior sobre o produto pesquisado, classificando de 1 a 7 , sendo 1 equivalente a nenhum conhecimento e 7 equivalentes a conhecimento avançado. Nessa questão, a média geral das respostas foi de 2,79, ou seja, uma média considerada baixa, o que denota que os respondentes possuíam pouco conhecimento sobre o produto pesquisado.

Por fim, na terceira questão, foi questionado se os participantes já haviam pesquisado o produto através da internet, as respostas distribuíram-se da seguinte forma: 68 pessoas afirmaram que nunca haviam pesquisado o produto através da internet até o momento do experimento, equivalendo a $97,1 \%$ da amostra. Já os $2,9 \%$ restantes, representados por 2 respondentes, afirmaram já ter efetuado a pesquisa.

As três questões apresentadas aqui são tratadas apenas para que se comprove que as mesmas não influenciaram no estudo, mais especificamente no efeito entre as variáveis dependente e independente. Assim, ao separar-se as respostas que poderiam influenciar, a análise das variáveis não apresentou diferença quando comparada ao total da amostra, comprovando, dessa forma, a não influência dessas respostas no todo da pesquisa.

\section{Resultados e Discussão}

Conforme os dados encontrados, no que tange à realidade do experimento, obteve-se uma média de 5,89 e um desvio padrão de 1,222 (sendo a escala definida como 1 - Nada parecido com a realidade e 7 - Muito parecido com a realidade), o que comprova que os respondentes perceberam o estudo realizado como sendo muito similar à realidade. Por se tratar de um estudo realizado em laboratório, tal resultado é de fundamental importância, pois confere confiabilidade nos demais resultados encontrados. Além disso, o experimento em laboratório permite isolar variáveis específicas, aumentando a validade interna do estudo, ou seja, cada causa identificada gera um efeito esperado (Nique \& Ladeira, 2014).

As variáveis denominadas "Intermediárias", replicadas de Dou et. al. (2010), podem ser observadas no Quadro 3. Nele, são apresentas a média e o desvio-padrão de cada questão que compõe essas variáveis e o índice de Confiabilidade Alfa. Estas variáveis mensuraram o conhecimento sobre buscadores na internet, bem como, o conhecimento de navegação na internet de um modo geral dos participantes da pesquisa. 
Quadro 3 - Variáveis intermediárias.

\begin{tabular}{|c|c|c|c|}
\hline Indicador & Média & Desvio Padrão & Alfa de Cronbach \\
\hline Variáveis intermediárias & 5,18 & 1,30 & \multirow[t]{9}{*}{$\mathbf{0 , 8 9 7}$} \\
\hline Com que frequência média você utiliza buscadores na internet? & 6,47 & 1,02 & \\
\hline $\begin{array}{l}\text { Como você classifica seu conhecimento sobre navegação na } \\
\text { internet de um modo geral? }\end{array}$ & 5,51 & 1,20 & \\
\hline $\begin{array}{l}\text { Como você se classificaria diante da colocação: "Eu sou } \\
\text { extremamente habilidoso em usar mecanismos de busca na } \\
\text { internet."? }\end{array}$ & 5,13 & 1,31 & \\
\hline $\begin{array}{l}\text { Como você se classificaria diante da colocação: "Eu me } \\
\text { considero bem informado sobre técnicas usadas por mecanismos } \\
\text { de busca na internet."? }\end{array}$ & 4,81 & 1,39 & \\
\hline $\begin{array}{l}\text { Como você se classificaria diante da colocação: "De certo modo, } \\
\text { eu possuo mais conhecimento que a maioria dos usuários sobre } \\
\text { mecanismos de busca na internet." }\end{array}$ & 4,61 & 1,55 & \\
\hline $\begin{array}{l}\text { Como você se classificaria diante da colocação: "Eu sei como } \\
\text { encontrar o que procuro usando mecanismos de busca na } \\
\text { internet." }\end{array}$ & 5,69 & 1,15 & \\
\hline $\begin{array}{l}\text { Como você se classificaria diante da colocação: "Comparando } \\
\text { com outras atividades que faço na web (ex.: e-mail, redes } \\
\text { sociais, etc.), eu sou tão habilidoso quanto em usar mecanismos } \\
\text { de busca na internet." }\end{array}$ & 5,23 & 1,29 & \\
\hline $\begin{array}{l}\text { Como você se classificaria diante da colocação: "Comparando } \\
\text { com outras habilidades que tenho (ex.: esportes, cozinhar, } \\
\text { cantar), eu sou tão habilidoso quanto em usar mecanismos de } \\
\text { busca na internet." }\end{array}$ & 4,67 & 1,35 & \\
\hline
\end{tabular}

Fonte: Dados da pesquisa (2019).

As médias comprovam que a maioria dos respondentes possuem um conhecimento médio/alto nesses quesitos. Um usuário com pouco conhecimento em navegação na internet, pode apresentar comportamento divergente em comparação a um usuário que possui alto conhecimento sobre o mesmo assunto, o que tornou a captação e análise das variáveis muito relevante, pois apresentam influência direta no resultado. A partir da análise das variáveis do Quadro 3, comprovou-se que não apresentaram influência na variável dependente.

Figura 3 - Comparação de média de links entre os grupos.

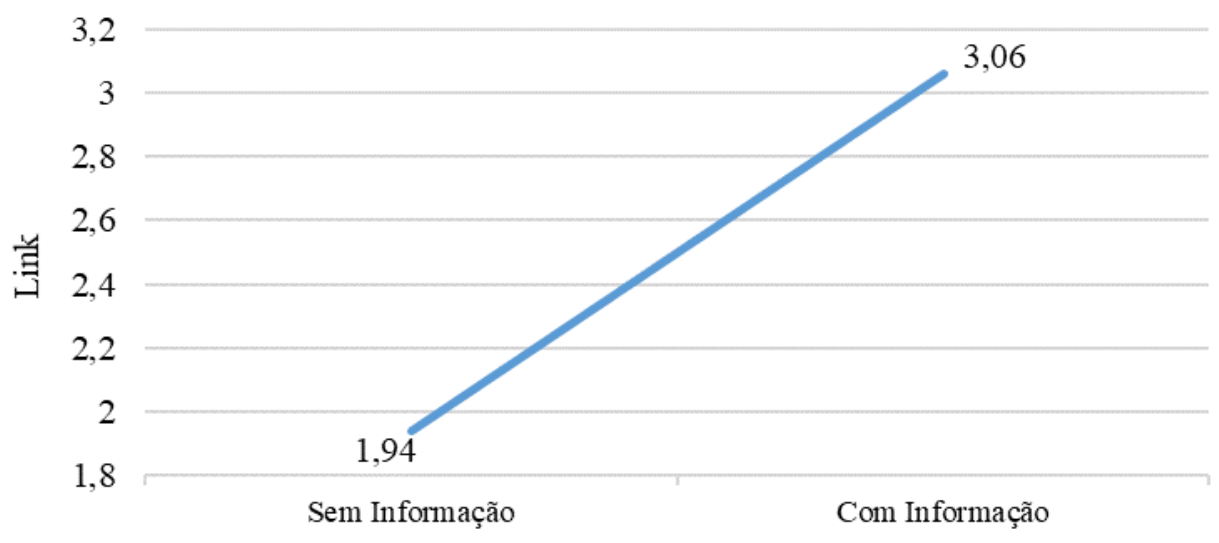

Fonte: Dados da pesquisa (2019). 
Conforme se observa na Figura 3, encontrou-se diferença estatisticamente significativa no comportamento dos respondentes ao escolher um website após a realização de uma busca na internet através de palavras-chave. A diferença apresentada pela média dos links foi de 1,12 com índice de significância igual a 0,000. Enquanto o grupo que não recebeu informação prévia obteve média de 1,94, dentre 6 opções de links disponíveis, o grupo que recebeu a informação prévia alcançou uma média de 3,06, dentre as mesmas 6 opções de links disponíveis. Dessa forma, pode-se concluir que indivíduos que possuem menos informações sobre determinado produto tendem a escolher opções de sites que aparecem em melhores posições nos resultados da busca.

Estes resultados corroboram com os resultados do estudo de Dou et. al. (2010), os quais demonstraram que indivíduos com informações prévias acerca de atributos de marcas, tendem a avaliar melhor marcas desconhecidas ao realizarem buscas em mecanismos de busca da internet, ou seja, a informação anterior influencia no comportamento de escolha dos indivíduos. Ainda, os achados de Walters e Hershfield (2020), os quais demonstraram que a existência ou não de informações (seja por desconhecimento ou esquecimento do consumidor) influenciam no comportamento dos consumidores nas suas tomadas de decisão, convergem com os resultados encontrados no presente estudo. Dessa forma, entende-se que os resultados encontrados confirmaram estudos anteriores que também tiveram como objeto de estudo a influência da informação prévia num determinado comportamento futuro do consumidor. Entretanto, considera-se um avanço na literatura os resultados encontrados neste estudo, por se tratar de um contexto de escolha de website em mecanismos de busca na internet, comportamento frequentemente executado pelos consumidores atualmente.

Figura 4 - Opções de link dos grupos.

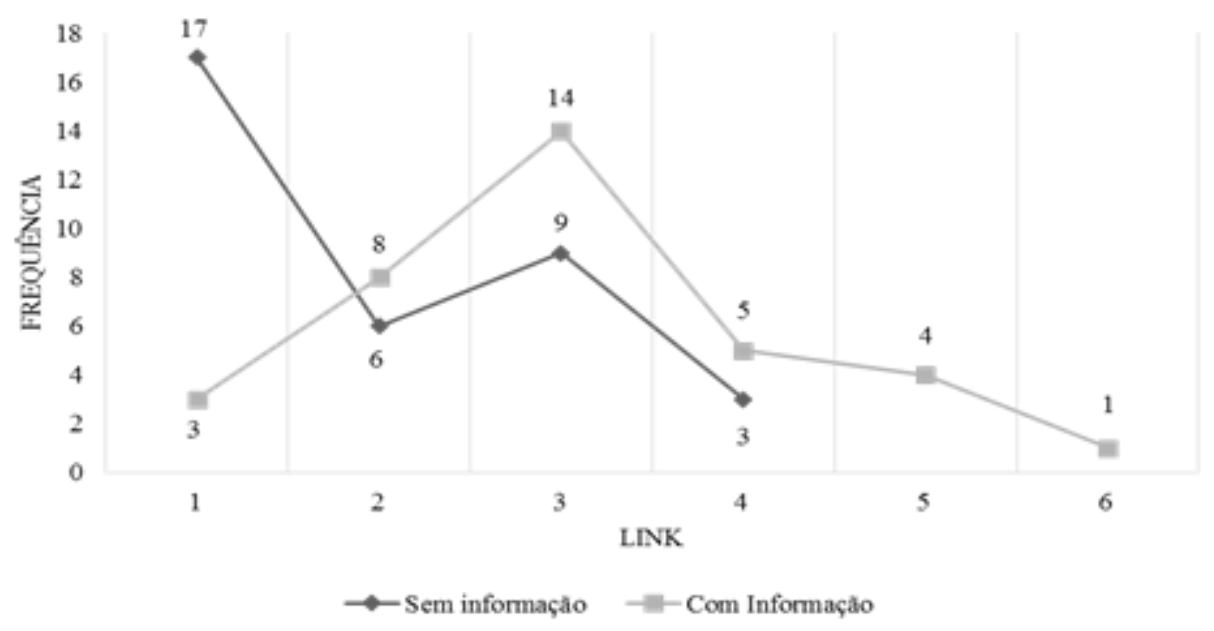

Fonte: Dados da pesquisa (2019).

A Figura 4 corrobora com os resultados apresentados anteriormente. Quando se analisa a distribuição dos "cliques" nos links disponíveis, percebe-se que o grupo "Sem informação" concentrou sua escolha no primeiro link, com dezessete escolhas, sem que nenhum respondente clicasse nos links 5 e 6. Em contrapartida, o grupo "Com informação" apresentou uma melhor distribuição das escolhas, sempre com ao menos uma escolha por link, sendo que a opção mais escolhida foi o link 3, com quatorze escolhas. Portanto, comprovou-se, estatisticamente, que o fato do indivíduo possuir uma informação prévia sobre um produto influencia diretamente na sua ação de escolha por um website, sendo este achado de grande relevância para a tomada de decisão das empresas ao terem seus websites listados em mecanismos de busca. 


\section{Considerações Finais}

Este estudo foi desenvolvido com o intuito de analisar cientificamente um comportamento de consumo extremamente corriqueiro no dia a dia dos indivíduos, afinal, conforme demonstrado, há um aumento no volume de e-commerce ano após ano. Além disso, para a realização destas compras pela internet, muitas vezes o início da jornada de compra ocorre quando o consumidor realiza a busca pelo produto desejado num mecanismo de busca na internet. Assim, compreender o que influencia a escolha do consumidor neste contexto, especificamente, a existência ou não de informações prévias sobre o produto, torna-se de grande relevância.

Neste sentido, o experimento usado para captar as variáveis mostrou que essa estratégia de marketing das empresas deve ser tomada como prioridade no momento em que as mesmas entram no mundo virtual. Pois, a localização do website no ranqueamento das páginas no mecanismo de busca influencia na escolha do consumidor por determinado link. Assim, através do trabalho constatou-se que, quando as pessoas possuem menos informações sobre algo, elas tendem a visitar os primeiros sites listados como resultados da busca. Para as empresas, estes resultados demonstram que as técnicas relativas à otimização da disposição do website nos mecanismos de busca precisam estar presentes nas ações de marketing implementadas por elas.

Estas conclusões são referendadas pela Figura 3, onde comprova-se que houve uma diferença estatisticamente significativa entre o grupo "Sem informação" e o grupo "Com informação". Esta diferença de 1,12 na média entre os dois grupos comprova que a informação prévia apresentou um efeito significativo no comportamento. Em relação às pessoas que não tiveram acesso à informação prévia, quase metade das pessoas clicaram no primeiro link e a variação entre os links escolhidos foi de 1 à 4. Já com o grupo de pessoas que teve a informação previamente apresentada, apresentaram o maior número de cliques no link 3 . Esta diferença mostrada pelo gráfico, quando analisada considerando cada um dos bilhões de acessos que os sites de pesquisa na internet processam por dia, permite compreender a relevância de estar apenas 1 link acima do concorrente nos resultados de busca.

Ainda no que tange à Figura 3, a mesma diferença entre os grupos permite concluir algo mais: pessoas com mais informação sobre o assunto tendem a serem mais analíticas ao escolherem seus acessos e, portanto, clicarem menos nos primeiros links e percorrerem mais as opções disponibilizadas na busca. Da mesma forma, esse dado pode ser utilizado pelas empresas nas suas tomadas de decisão em relação às estratégias de marketing.

O presente estudo usou como variável dependente a informação sobre o produto, elemento cada vez mais disponível para os consumidores. Entretanto, entende-se que outras variáveis de influência também devem ser estudadas. Desta forma, sugere-se que a influência de elementos como a disposição das informações, não em posicionamento, mas em forma de apresentação (letras maiúsculas ou minúsculas, fotos, cores, etc.), buscando identificar o que desperta a atenção do indivíduo na hora do clique, sejam mensurados. Ou seja, estudos futuros poderão abordar a influência da disposição das informações no comportamento de escolha dos usuários de mecanismos de busca. Além disso, recomenda-se que sejam feitos trabalhos futuros que foquem no estudo de medições para mobile e redes sociais, visando identificar diferenças de comportamento dos indivíduos ao acessarem um mecanismo de busca através do celular, bem como a pesquisa por empresas nas redes sociais. A migração do consumo para a web, o consumo em tempo real, as facilidades de buscas por melhores produtos e referências; assumem-se como tendências irreversíveis, que exigem das organizações estratégias mercadológicas eficientes. Assim, tornase primordial gerenciar a comunicação empresarial na "Era da busca" exigindo uma postura de atualização permanente e estratégias de marketing dirigidas e sustentáveis.

Portanto, reforçando, conclui-se que a localização do website de uma empresa na página de um site de pesquisa na web influencia diretamente no comportamento do consumidor em clicar no link ou não. Assim, evidenciou-se no estudo que quando o consumidor não possui muitas informações sobre o produto que está pesquisando, a tendência é ele clicar nas primeiras opções de site apresentadas. Em contrapartida, quando ele possui mais informações acerca do produto pesquisado, a 
tendência é que ele percorra mais opções de site e não fique restrito às opções localizadas no topo da página.

\section{Referências}

Aswani, R., Kar, A. K., Ilavarasan, P. V., \& Dwivedi, Y. K. (2018). Search engine marketing is not all gold: Insights from Twitter and SEOClerks. International Journal of Information Management, 38(1), 107-116.

Aswani, R., Ghrera, S. P., Chandra, S., \& Kar, A. K. (2021). A hybrid evolutionary approach for identifying spam websites for search engine marketing. Evolutionary Intelligence, 14(4), 1803-1815.

Colmenero-Ferreira, F., \& Oliveira, A. A. D. (2012). Os sistemas de recomendação na web como determinantes prescritivos na tomada de decisão. JISTEMJournal of Information Systems and Technology Management, 9, 353-368.

Dou, W., Lim, K. H., Su, C., Zhou, N., \& Cui, N. (2010). Brand positioning strategy using search engine marketing. MIS quarterly, $261-279$.

Ebit Nielsen (2021) <http://www.ebit.com.br>.

Gil, A. C. (2008). Métodos e técnicas de pesquisa social. (6a ed.), Editora Atlas SA.

Ghose, A., Ipeirotis, P. G., \& Li, B. (2014). Examining the impact of ranking on consumer behavior and search engine revenue. Management Science, 60(7), $1632-1654$.

Godey, B., Manthiou, A., Pederzoli, D., Rokka, J., Aiello, G., Donvito, R., \& Singh, R. (2016). Social media marketing efforts of luxury brands: Influence on brand equity and consumer behavior. Journal of business research, 69(12), 5833-5841.

Jansen, B. J., \& Molina, P. R. (2006). The effectiveness of Web search engines for retrieving relevant ecommerce links. Information Processing \& Management, 42(4), 1075-1098.

Kivetz, R., \& Simonson, I. (2000). The effects of incomplete information on consumer choice. Journal of marketing research, 37(4), 427-448.

Krishen, A. S., Dwivedi, Y. K., Bindu, N., \& Kumar, K. S. (2021). A broad overview of interactive digital marketing: A bibliometric network analysis. Journal of Business Research, 131, 183-195.

Malhotra, N. K. (2012). Pesquisa de Marketing-: uma orientação aplicada. Bookman Editora.

Mieli, M., \& Zillinger, M. (2020). Tourist information channels as consumer choice: The value of tourist guidebooks in the digital age. Scandinavian Journal of Hospitality and Tourism, 20(1), 28-48.

Nique, W., \& Ladeira, W. (2014). Pesquisa de marketing: uma orientação para o mercado brasileiro. Atlas.

Okada, S. I., \& De Souza, E. M. S. (2011). Estratégias de marketing digital na era da busca. Revista Brasileira de Marketing, 10(1), 46-72.

Rusmee, K., \& Chumuang, N. Predicting System for the Behavior of Consumer Buying Personal Car Decision by Using SMO. In 2019 14th International Joint Symposium on Artificial Intelligence and Natural Language Processing (iSAI-NLP) (pp. 1-6). IEEE.

Salerno, A., Laran, J., \& Janiszewski, C. (2015). Pride and regulatory behavior: The influence of appraisal information and self-regulatory goals. Journal of Consumer Research, 42(3), 499-514.

Saura, J. R. (2021). Using data sciences in digital marketing: Framework, methods, and performance metrics. Journal of Innovation \& Knowledge, 6(2), 92102.

Sen, R. (2005). Optimal search engine marketing strategy. International Journal of Electronic Commerce, 10(1), 9-25.

Terrance, A. R., Shrivastava, S., \& Kumari, A. (2017, December). Importance of Search Engine Marketing in the Digital World. In ICITKM (pp. 155-158).

Terrance, A. R., Shrivastava, S., Kumari, A., \& Sivanandam, L. (2018). Competitive Analysis of Retail Websites through Search Engine Marketing. Ingeniería Solidaria, 14(25), 1-14.

Thaha, A. R., Maulina, E., Muftiadi, R. A., \& Alexandri, M. B. (2021). Digital marketing and SMEs: a systematic mapping study. Library Philosophy and Practice (e-journal), 5113 .

Vaz, C. A. (2009). Google Marketing-O Guia Definitivo de Marketing Digital. Novatec Editora.

Walters, D. J., \& Hershfield, H. E. (2020). Consumers Make Different Inferences and Choices When Product Uncertainty Is Attributed to Forgetting Rather than Ignorance. Journal of Consumer Research, 47(1), 56-78.

Zhang, J., \& Dimitroff, A. (2005). The impact of webpage content characteristics on webpage visibility in search engine results (Part I). Information Processing \& Management, 41(3), 665-690. 